\title{
Witzel Catheter Feeding Jejunostomy: Is It Safe?
}

\author{
Donatas Venskutonis $^{\text {a }}$ Saulius Bradulskis ${ }^{a}$ Kestutis Adamonis ${ }^{b}$ \\ Linas Urbanavicius ${ }^{a}$ \\ Clinics of ${ }^{\mathrm{a}}$ General Surgery and ${ }^{\mathrm{b}}$ Gastroenterology, Kaunas University of Medicine, Kaunas, Lithuania
}

\section{Key Words}

Witzel catheter feeding jejunostomy · Jejunostomy

feeding-related complications, onset $\cdot$ Enteral feeding

\begin{abstract}
Background/Aims: Patients often suffer from malnutrition after digestive tract surgery. It leads to a longer recovery and a higher rate of postoperative complications. Early postoperative jejunostomy feeding is a way of tackling this problem. Opinions emerge that feeding via jejunostomy catheter is not the ideal method because of its complications. Our aim was to assess a complication rate of longitudinal Witzel catheter feeding jejunostomy and complications related to the onset of enteral feeding. Methods: A retrospective analysis of case histories of 136 patients operated on for upper digestive tract diseases at our clinic between 1992 and 2004 with catheter feeding jejunostomy as an adjunct. We interviewed our patients by telephone about the jejunostomy-related complications during the 1st postoperative year. Results: We observed two feeding jejunostomy-related complications (1.5\%). Complications related to the onset of enteral feeding were observed in 12 cases (26.7\%). There was no mortality. No complication of catheter jejunostomy was observed during the 1st postoperative year. Conclusions: A longitudinal Witzel catheter jejunostomy feeding is beneficial after surgery of the upper digestive tract. It is a rather safe procedure, which can be safely started on the day of operation.

Copyright $\odot 2007$ S. Karger AG, Basel
\end{abstract}

\section{Introduction}

Patients operated on for upper digestive tract diseases often face nutritional disorders. When no measures are taken, malnutrition grows in the postoperative period due to insufficient feeding determined by the disease and the extent of operation. This is associated with a longer recovery and a higher rate of postoperative complications. The impact of nutritional status on the outcome of digestive surgery is well known and the ways to solve the problem of malnutrition are widely searched. One of the solutions is an early postoperative jejunostomy feeding [1-3].

The jejunostomy longitudinal and transverse Witzel technique was introduced into clinical practice in 1891. A needle catheter jejunostomy technique was described by Delany in 1973. According to some authors [4], the technique described by Delany is more reliable and has fewer complications. The drawback of this technique is its expensiveness determined by the necessity of a special kit.

Opinions emerge that feeding via jejunostomy catheter is not the ideal method because of its complications that sometimes lead to relaparotomy. Some authors even get disappointed about this method [5]. Braga et al. [6] compiled complication rates from 14 studies with more than 100 cases each with a total count of 4,961 feeding jejunostomies and found an overall complication rate of $2.9 \%$ irrespective of the technique used. In their study, they analyzed 402 cases of Witzel catheter feeding jeju-

Donatas Venskutoni

Kaunas University of Medicine

Clinic of General Surgery, Kaunas 2nd Clinical Hospital

Josvainiu str. 2, LT-47133 Kaunas (Lithuania)

Tel. +370 3730 6022, Fax +370 3730 6066, E-Mail donas@medi.lt 
nostomy and found that 11 patients $(2.7 \%)$ experienced complications, of these, 7 (1.7\%) underwent relaparotomy, i.e. the complication rate using this technique was lower. Comparison of Witzel catheter feeding jejunostomy and needle catheter feeding jejunostomy performed by the same surgeon revealed a lower complication rate after a needle catheter jejunostomy procedure [7].

Considering the reports mentioned above, the question arises whether Witzel catheter feeding jejunostomy is a reliable and safe procedure. In the medical literature of the last 3 years we have found no data concerning results of Witzel catheter feeding jejunostomy. The aim of this study was to present our data on complications of the longitudinal Witzel catheter feeding jejunostomy procedure and on complications associated with the onset of postoperative feeding via jejunostomy catheter.

\section{Patients and Methods}

\section{Patients}

136 patients were operated on for upper digestive tract diseases who had received a catheter feeding jejunostomy as an additional procedure over a 12-year period between 1992 and 2004 at the Clinic of General Surgery of Kaunas University of Medicine.

\section{Methods}

A retrospective analysis of case histories: Postoperative catheter feeding jejunostomy-related complications and complications related to the onset of jejunostomy feeding were studied. The following jejunostomy-related complications were recorded: leakage at jejunostomy catheter site, jejunostomy catheter site infection, dislodgement of the jejunostomy catheter and spillage of the bowel contents into the abdominal cavity, jejunostomy-related peritonitis, jejunostomy-related mechanical ileus (interposition of the small intestine between the jejunostomy loop and the large bowel), occlusion of the catheter. The following complications related to the onset of enteral feeding were recorded: diarrhea, nausea, vomiting, abdominal colic and distention. All patients were interviewed by phone about the occurrence of Witzel catheter jejunostomy-related complications during the 1st postoperative year.

We used a B. Braun Melsungen AG 10-Ch jejunostomy catheter. A longitudinal Witzel jejunostomy technique was employed. A jejunal loop 25-30 cm below the ligament of Treitz was chosen. The 4/0 Vicryl purse-string suture was applied around the catheter site on the antimesenteric margin of the intestine. The lumen of the small intestine was opened by means of an electric scalpel. The catheter was inserted $15-20 \mathrm{~cm}$ distalwards, and then the pursestring suture was secured in place. A serosal tunnel was employed for the catheter in the small intestine $3-5 \mathrm{~cm}$ proximally from the catheter's exit site using a continuous suture. The catheter was then delivered through the abdominal wall via a separate stab incision. The jejunal loop around the catheter exit site was fixated to the peritoneum of internal abdominal wall with several $(n=6)$ interrupted sealing sutures isolating the catheter from the peritoneal cavity, and the catheter was additionally fixed to the skin.
Table 1. Indications for surgical treatment

\begin{tabular}{ll}
\hline Surgical pathology & Patients \\
\hline Severe necrotizing pancreatitis & 46 \\
Bleeding from gastric or duodenal ulcer & 32 \\
Perforated gastric or duodenal ulcer & 30 \\
Suture dehiscence after gastric resection for a & \\
$\quad$ bleeding ulcer & 71 \\
Gastric cancer & 4 \\
Pancreas cancer with duodenal stenosis & 3 \\
Chemical burns of esophagus and stomach & 3 \\
Other & 136 \\
\hline Total & \\
\hline
\end{tabular}

Table 2. Types of operations with a longitudinal Witzel catheter feeding jejunostomy as an additional procedure

\begin{tabular}{lc}
\hline Surgical operation & Patients \\
\hline Bilroth I gastric resection & 53 \\
Necrectomy and drainage for acute pancreatitis & 46 \\
Drainage of abdominal cavity for necrotizing & 11 \\
$\quad$ pancreatitis & 8 \\
Bilroth II gastric resection & 8 \\
Closure of perforated gastric or duodenal & \\
$\quad$ ulcer and drainage of abdominal cavity & 4 \\
Gastroenterostomy for pancreatic cancer with & 6 \\
$\quad$ duodenal stenosis & 136 \\
\hline Other & \\
\hline Total &
\end{tabular}

Statistical Analysis

Statistical analysis was performed with commercially available statistical analysis software (SPSS 13). Results are reported as mean and range values. Statistical significance was accepted at $\mathrm{p}<0.05$.

\section{Results}

Over the period 1992-2004, 136 patients received catheter feeding jejunostomy after operations of the stomach, duodenum and pancreas. Experienced surgeons of our clinic performed all operations. The indications for surgery are shown in table 1 . The types of operations are shown in table 2 . The mean age of our patients was 64 years (range 36-86). The mean duration of jejunostomy feeding was 14 days (range 2-69) (fig. 1). 
Fig. 1. Duration of catheter jejunostomy feeding.

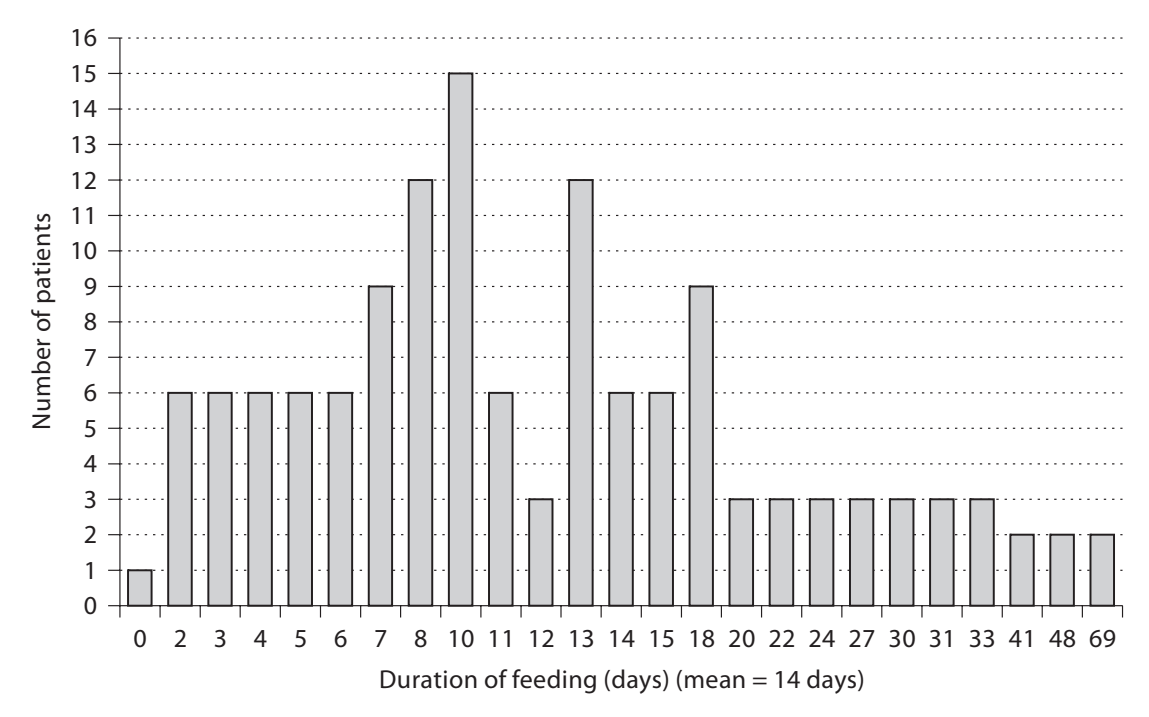

Table 3. Jejunostomy-related complications $(\mathrm{n}=136)$

\begin{tabular}{lcc}
\hline Type of complication & $\mathrm{n}$ & $\%$ \\
\hline Feeding catheter withdrawal & 1 & 0.7 \\
Mechanical ileus & 1 & 0.7 \\
\hline Overall & 2 & 1.5
\end{tabular}

In 24 cases (17.7\%), feeding via a jejunostomy catheter was initiated on the day of operation, in 99 cases $(72.8 \%)$ on postoperative day 1,11 patients $(8.1 \%)$ were started to be fed on postoperative days 2 and 3,1 patient $(0.7 \%)$ on postoperative day 6 , and 1 patient $(0.7 \%)$ was not fed. We started to feed in case of absent abdominal colic, distention, liquid sequestration inside the bowel lumen, and if there were no hyperactive bowel sounds. The enteral feeding was initiated on postoperative days 2-3 in cases where the patients were hemodynamically unstable due to the massive blood loss preoperatively or other reasons. One patient remained hemodynamically unstable, and died despite all our efforts, and therefore the feeding was not initiated but no jejunostomy-related complication was defined. We always started enteral feeding with intrajejunal infusion of Ringer's or a 5\% glucose solution and continued with the standard Semper or Nutricia enteral nutrition solutions. The infusion was started at a flow rate of $20-40 \mathrm{ml} / \mathrm{h}$. On the second day, if the infusion was well tolerated, we administered the enteral feed
Table 4. Complications related to the onset of jejunostomy feeding

\begin{tabular}{|c|c|c|c|c|c|c|}
\hline \multirow[t]{2}{*}{$\begin{array}{l}\text { Type of } \\
\text { complication }\end{array}$} & \multicolumn{2}{|c|}{$\begin{array}{l}\text { Group } 1^{\mathrm{a}} \\
(\mathrm{n}=24)\end{array}$} & \multicolumn{2}{|c|}{$\begin{array}{l}\text { Group } 2^{b} \\
(n=21)\end{array}$} & \multicolumn{2}{|c|}{$\begin{array}{l}\text { Total } \\
(\mathrm{n}=45)\end{array}$} \\
\hline & $\mathrm{n}$ & $\%$ & $\mathrm{n}$ & $\%$ & $\mathrm{n}$ & $\%$ \\
\hline Diarrhea & 1 & 4.2 & 1 & 4.8 & 2 & 4.4 \\
\hline Nausea & 1 & 4.2 & 1 & 4.8 & 2 & 4.4 \\
\hline Vomiting & 1 & 4.2 & 0 & 0 & 1 & 2.2 \\
\hline Abdominal colic & 2 & 8.3 & 2 & 9.5 & 4 & 8.9 \\
\hline Abdominal distention & 1 & 4.2 & 2 & 9.5 & 3 & 6.7 \\
\hline Overall & $6^{\mathrm{c}}$ & 25 & 6 & 28.6 & 12 & 26.7 \\
\hline
\end{tabular}

a Onset of feeding on the day of operation.

${ }^{\mathrm{b}}$ Onset of feeding on postoperative days 1-4. ${ }^{\mathrm{c}} \mathrm{p}=0.72$ vs. group 2 .

diluted with sterile water $1: 1$ at a flow rate of $40 \mathrm{ml} / \mathrm{h}$. On the third day we increased the flow rate to $60 \mathrm{ml} / \mathrm{h}$. On the fourth day we continued with a non-diluted enteral feed intrajejunally. The further increase in flow rate depended on the patients' needs. The feeding catheter was withdrawn only when oral nutrition was sufficient. In case of postoperative complications, we continued the jejunostomy feeding until the patients' full regression.

We observed two feeding jejunostomy-related complications (table 3 ). In 1 case the feeding catheter withdrawal and spillage of the feeding solution into the abdominal cavity was encountered. In the second case the small 
bowel loop interposed between the jejunostomy loop and the large bowel causing mechanical ileus 6 weeks after the procedure. Both patients underwent relaparotomy. The subsequent postoperative course was complication-free. There was no feeding jejunostomy-related mortality. The overall complication rate was $1.5 \%$. No patient was readmitted for feeding jejunostomy-related complications during the 1st postoperative year.

45 patients were observed for complications related to the onset of enteral feeding (table 4). 24 patients (group 1) were started to be fed early on the day of operation. In 21 cases (group 2) the feeding was started on postoperative days 1-4: 10 patients on postoperative day 1, 7 patients on postoperative day 2,3 patients on postoperative day 3 , and 1 patient on postoperative day 4 . Complications comprised diarrhea, nausea, vomiting, abdominal colic and distention.

In total, 12 patients $(26.7 \%)$ faced complications related to the onset of enteral feeding. Six early complications were encountered in group 1 (25\%). Six patients faced complications in group $2(28.6 \%)$. The difference between the groups is not statistically significant $(\mathrm{p}=$ 0.72 ), however, complications related to the onset of enteral feeding were less frequent in group 1 where feeding was started early. In case of complications, we always reduced the flow rate of enteral feed until its regression, and then gradually increased it in order to meet the individual patient's demands. The individual target intake was achieved in all cases. All patients recovered without further interventions.

\section{Discussion}

Perioperative nutrition has, during the past century, been transformed from the only tool to provide calorie and nitrogen support to a tool to boost the immune system and increase resistance to complications [8]. Enteral tube feeding is more physiologic than parenteral feeding and it stimulates an adequate immune response to operative treatment [9-11].

Despite publications showing good results of an early postoperative feeding via intrajejunal tube, surgeons still have a rather conservative approach as far as jejunostomy feeding early after the operation is concerned $[8,12]$. Necessity of additional manipulation, fear of suture dehiscence and other possible complications, and belief that the bowel function is insufficient postoperatively are drawbacks considered.
Studies show that early enteral feeding after abdominal surgery is safer and cost-effective compared to a total parenteral nutrition [13-16]. Bengmark et al. [17] showed that interrupted enteral nutrition has negative consequences, such as impaired gastrointestinal secretion, motility and blood supply, increased virulence of pathogenic microorganisms, atrophy of gastrointestinal mucosa with enhanced risk of bacterial translocation, impaired transport of antioxidants, flavonoids, phytoestrogens and other factors, and increases the risk of postoperative septic complications. Currently the benefits of enteral tube feeding in case of acute necrotizing pancreatitis are well known [18], namely the enteral tube feeding should be one of the main methods of nutrition in case of acute pancreatitis since it modulates the inflammatory and sepsis response, lowers the CRP level and the multiple organ failure score more efficiently compared to a total parenteral nutrition $[19,20]$. Harrison et al. [21] showed that early postoperative enteral tube feeding has positive effects on the metabolism of proteins.

Braga et al. [6] observed 2.7\% $(n=402)$ feeding jejunostomy-related complications following the same catheter feeding jejunostomy procedure. Sarr [22] analyzed results of 500 needle catheter jejunostomies performed after abdominal operations. Only 1 patient faced obstruction of the small intestine and 2 cases of intestinal pneumatosis were observed with an overall complication rate of only $0.6 \%$. Tapia et al. [4] found a $2.1 \%$ complication rate following the longitudinal Witzel jejunostomy procedure. Therefore, the conclusion made by Ingrid et al. [5] that feeding jejunostomy is not a safe technique is too skeptical. On the other hand, nasoenteral tube feeding is associated with significant patient discomfort, epistaxis, sinusitis, inadvertent tube removal, tube clogging, dislodgement of the tube and risk of discontinuation of enteral feeding and a small bowel obstruction with a dislodged feeding tube [23, 24]. This encourages us to give priority to enteral feeding compared to a total parenteral nutrition in the postoperative period when the bowel function is not compromised $[25,26]$. In our study we observed only 2 complications out of 136 cases (1.5\%). This is less than is found in the majority of analyzed literature sources. The most important indications for catheter feeding jejunostomy in our cases were operations for perforated gastric and duodenal ulcer (30 patients), gastrointestinal bleeding (32 patients) and severe acute necrotizing pancreatitis (46 patients) (table 1). All our patients were in a serious general medical condition. The cited authors performed feeding jejunostomies after bigger operations such as gastrectomy, esophageal resection, pancreatoduodenectomy [6]. 
We experienced no case of suture dehiscence. In 11 cases we performed a catheter feeding jejunostomy during relaparotomy for suture dehiscence and this was essential for recovery of the patients. The study of Sand et al. [27] proved that early postoperative jejunostomy feeding is not associated with an increased rate of suture dehiscence. This is also confirmed by other studies $[28,29]$. We believe that early enteral feeding is safe and can be started on the day of operation. It is not associated with higher complication rates compared to the jejunostomy feeding started on postoperative days $2-4$. Our results are similar to those described in the literature [30].
On the basis of the aforementioned, we conclude that the longitudinal Witzel catheter jejunostomy feeding is beneficial and well tolerated by patients in the postoperative period in case of malnutrition, severe necrotizing pancreatitis, and suture dehiscence after surgery for gastroduodenal ulcer disease, and when there is a high risk of postoperative complications. In our experience, it is a rather safe manipulation when performed using modern equipment and suture materials, which often helps to solve the problem of malnutrition in the postoperative period. It is safe to start a jejunostomy feeding on the day of operation and this is not associated with a higher rate of complications related to the onset of enteral feeding.

\section{References}

-1 Weimann A, Braunert M, Muller T, Bley T, Wiedemann B: Feasibility and safety of needle catheter jejunostomy for enteral nutrition in surgically treated severe acute pancreatitis. JPEN 2004;28:324-327.

-2 Stamenekovic D, Basic M, Palibrk I, Jankovic $\mathrm{Z}$ : Enteral nutrition and surgical patient. Acta Chir Iugosl 2003;50:109-113.

$\checkmark 3$ Chin KF, Townsend S, Wong W, Miller GV: A prospective cohort study of feeding needle catheter jejunostomy in an upper gastrointestinal surgical unit. Clin Nutr 2004;23: 691-696.

-4 Tapia J, Murguia R, Garcia G, de los Monteros PE, Onate E: Jejunostomy: techniques, indications and complications. World J Surg 1999;23:596-602.

$\checkmark 5$ Ingrid JM, Han-Geurts IJ, Verhoef C, Tilanus HW: Relaparatomy following complications of feeding jejunostomy in esophageal surgery. Dig Surg 2004;21:192-196.

-6 Braga M, Gianotti L, Gentilini O, Liotta S, Di Carlo V: Feeding the gut early after digestive surgery: results of a nine-year experience. Clin Nutr 2002;21:59-65.

$\checkmark 7$ Holmes JH 4th, Brundage SI, Yuen P, Hall RA, Maier RV, Jurkovich GJ: Complications of surgical feeding jejunostomy in trauma patients. J Trauma 1999;47:1009-1012.

$\checkmark 8$ Bengmark S: Enteral nutrition in HPB surgery: past and future. J Hepatobiliary Pancreat Surg 2002;9:448-458.

-9 Gianotti L, Alexander JW, Nelson JL, Fukushima R, Pyles T, Chalk CL: Role of early enteral feeding and acute starvation on postburn bacterial translocation and host defense: prospective, randomized trials. Crit Care Med 1994;22:265-272.

$>10$ Johnson CD, Kudsk KA: Nutrition and intestinal mucosal immunity. Clin Nutr 1999;18: 337-344.

11 Cunningham-Rundles S, Lin DH: Nutrition and the immune system of the gut. Nutrition $1998 ; 14: 573-579$.
12 Dolp R, Wiedeck H, Ahnefeld FW, Grunert A: Enteral feeding. New technics and feeding mixtures. Infusionsther Klin Ernähr 1981;8: 22-26.

13 Carr CS, Ling KD, Boulos P, Singer M: Randomised trial of safety and efficacy of immediate postoperative enteral feeding in patients undergoing gastrointestinal resection. BMJ 1996;312:869-871.

14 Velez JP, Lince LF, Restrepo JI: Early enteral nutrition in gastrointestinal surgery: a pilot study. Nutrition 1997;13:442-445.

15 Papapietro K, Marin M, Diaz E, Watkins G, Berger Z, Rappoport J: Digestive refeeding in acute pancreatitis. When and how? Rev Med Chil 2001;129:391-396.

16 Bozzetti F, Braga M, Gianotti L, Gavazzi C, Mariani L: Postoperative enteral versus parenteral nutrition in malnourished patients with gastrointestinal cancer: a randomised multicentre trial. Lancet 2001;358:1487-1492.

17 Bengmark S, Andersson R, Mangiante G Uninterrupted perioperative enteral nutrition. Clin Nutr 2001;20:11-19.

18 Wyncoll DL: The management of severe acute necrotising pancreatitis: an evidencebased review of the literature. Intensive Care Med 1999;25:146-156.

19 Windsor AC, Kanwar S, Li AG, Barnes E, Guthrie JA, Spark JI, Welsh F, Guillou PJ, Reynolds JV: Compared with parenteral nutrition, enteral feeding attenuates the acute phase response and improves disease severity in acute pancreatitis. Gut 1998;42:431435.

20 Weimann A, Braunert M, Muller T, Bley T, Wiedemann B: Feasibility and safety of needle catheter jejunostomy for enteral nutrition in surgically treated severe acute pancreatitis. JPEN 2004;28:324-327.

21 Harrison LE, Hochwald SN, Heslin MJ, Berman R, Burt M, Brennan MF: Early postoperative enteral nutrition improves peripheral protein kinetics in upper gastrointestinal cancer patients undergoing complete resection: a randomized trial. JPEN 1997;21:202207.

22 Sarr MG: Appropriate use, complications and advantages demonstrated in 500 consecutive needle catheter jejunostomies. $\mathrm{Br} \mathrm{J}$ Surg 1999;86:557-561.

$\checkmark 23$ Kamar M, Bar-Dayan A, Zmora O, Ayalon A: Small bowel obstruction from a dislodged feeding tube. Age Ageing 2004;33:81-82.

24 Baskin WN: Acute complications associated with bedside placement of feeding tubes. Nutr Clin Pract 2006;21:40-55.

25 Klein S, Kinney J, Jeejeebhoy K, Alpers D, Hellerstein M, Murray M, Twomey P: Nutrition support in clinical practice: review of published data and recommendations for future research directions. National Institutes of Health, American Society for Parenteral and Enteral Nutrition, and American Society for Clinical Nutrition. JPEN 1997;21: 133-156.

26 Papapietro K, Diaz E, Csendes A, Diaz JC, Burdiles P, Maluenda F, Braghetto I, Llanos JL, D'Acuna S, Rappoport J: Early enteral nutrition in cancer patients subjected to a total gastrectomy. Rev Med Chil 2002;130:11251130 .

27 Sand J, Luostarinen M, Matikainen M: Enteral or parenteral feeding after total gastrectomy: prospective randomised pilot study. Eur J Surg 1997;163:761-766.

28 Carr CS, Ling KD, Boulos P, Singer M: Randomised trial of safety and efficacy of immediate postoperative enteral feeding in patients undergoing gastrointestinal resection. BMJ 1996;312:869-871.

29 Velez JP, Lince LF, Restrepo JI: Early enteral nutrition in gastrointestinal surgery: a pilot study. Nutrition 1997;13:442-445.

30 Bertullo H, Olano E, Ferradas A, Barrial N, Tihista S: Surgical jejunostomy as a route for enteral nutrition. Nutr Hosp 1995;10:110114. 